\title{
Pencapaian Kepentingan Korea Selatan melalui Diplomasi Publik Korean Wave
}

\author{
Sofia Trisni, Rika Isnarti, Anita Afriani \& Ferdian \\ Universitas Andalas
}

\begin{abstract}
ABSTRAK
Diplomasi publik merupakan instrumen pencapaian kepentingan negara yang populer digunakan, Korea Selatan merupakan salah satu contoh negara yang menggunakan diplomasi publik dengan Korean wave menjadi salah satu medianya. Diplomasi publik Korean wave meraih kesuksesannya di Indonesia secara umum dan kota Padang secara khusus. Tulisan ini bertujuan untuk mendeskripsikan pencapaian kepentingan negara melalui pelaksanaan diplomasi publik yang melibatkan banyak aktor swasta/private. Penulis menggunakan metode survei ke sepuluh universitas yang ada di kota Padang untuk mengetahui pencapaian kepentingan negara ini di kota Padang. Tulisan ini menemukan bahwa walaupun diplomasi publik ini berhasil dalam meningkatkan popularitas Korea Selatan, tetapi kepentingan yang ingin dicapai seperti tersosialisasikannya kebijakan pemerintah dan penciptaan image Korea Selatan yang cinta damai dan attractive belum berhasil tercapai sepenuhnya, karena ketertarikan kepada budaya populer yang ditawarkan ternyata tidak berhasil untuk menarik pemuda kota Padang untuk lebih lanjut mempelajari kebijakan-kebijakan pemerintah dan membangun image yang diinginkan oleh pemerintah.
\end{abstract}

Kata-kata kunci : Diplomasi Publik, Korean wave, image, budaya populer, Padang

Public Diplomacy is a popular instrument in achieving national interest and Republic of Korea is an example of country that employ public diplomacy with Korean wave as one of its media. As a tool of public diplomacy, Korean wave manages to achieve success in Indonesia generally and Padang specifically. This article aims to describe achievement of national interest through the implementation of public diplomacy that involve private actors. Authors use survey to ten universities in Padang as a method to answer the question. This article finds that although Korean wave is able to gain massive succes, Republic of Korea national interest such as sosialization of policy, image formation as a peaceful country and attractive image cannot be fully achieved. We found that big attention to cultural product cannot attract the youth in Padang to further learn policies of Republic of Korea.

Keywords: Public Diplomacy, Korean wave, image, populer culture, Padang 
Diplomasi Publik merupakan sebuah instrumen yang populer digunakan untuk mencapai kepentingan negara dengan cara menjangkau publik asing; seiring berkembangnya pemikiran bahwa memenangkan hati dan pikiran publik asing akan dapat memudahkan negara untuk mencapai kepentingannya (Nye 2009). Nye (2009) berargumen bahwa daya tarik dapat digunakan untuk mempengaruhi publik asing, yang lebih lanjut dapat menghasilkan soft power bagi negara tersebut. Pendekatan dengan menggunakan kekerasan banyak menimbulkan kerugian, sehingga negara lebih memilih menggunakan daya tarik daripada kekerasan dalam mencapai kepentingannya.

Salah satu negara Asia yang giat dalam melaksanakan Diplomasi Publik adalah Korea Selatan atau yang dikenal dengan nama resmi Republic of Korea, yang merasa bahwa citra mereka tidak sebaik performa perkembangan perekonomiannya. Keinginan untuk menyamakan laju perkembangan ekonomi dan perbaikan citra inilah yang membuat Korea Selatan serius dalam melaksanakan diplomasi publik. Bukti nyata keseriusan pemerintah Korea Selatan dalam menggunakan diplomasi publik sebagai alat pencapaian kepentingan terlihat dari meningkatnya alokasi dana pelaksanaan diplomasi publik dari tahun ke tahun (MoFA Republic of Korea). Tidak hanya itu, pemerintah Korea Selatan dengan tegas menyatakan bahwa mereka akan berfokus pada pelaksanaan diplomasi publik dengan melibatkan berbagai pihak yang salah satunya dilaksanakan dengan menggunakan Korean wave (MoFA Republic of Korea).

Korean wave merupakan sebuah fenomena yang dialamatkan kepada boomingnya produk-produk budaya Korea seperti drama, musik, film dan makanan. Salah satu drama yang meledak di pasaran adalah Jewel in the Palace yang mencapai kepopuleran yang luar biasa di Asia Timur dan Asia Tenggara (Elfing-Hwang 2013). Jewel in the Palace dinilai mampu menyampaikan nilai-nilai yang ingin diperlihatkan oleh pemerintah Korea Selatan, seperti keindahan budaya, keanekaragaman dan kelezatan makanan, keindahan alam dan kemajuan teknik pengobatan tradisional yang mereka miliki (Cheng 2008). Drama ini tercatat sebagai drama yang telah di siarkan di sekitar 87 negara di dunia (Tuk 2013) termasuk Indonesia. Jeong, Lee dan Lee (2017) menemukan bahwa drama Korea ini memberikan pengaruh yang kuat kepada penontonnyadi Jakarta yang menumbuhkan rasa ke-Korea-an yang membuat mereka secara konstan tetap mengkonsumsi drama Korea. Produk drama seperti ini merupakan salah satu bagian dari Korean wave yang dikatakan sebagai elemen dari diplomasi publiknya oleh pemerintah Korea Selatan.

Pada awal kelahirannya, diplomasi publik merupakan sebuah upaya yang dilaksanakan oleh pemerintah untuk menjangkau publik asing dengan tujuan agar publik asing dapat memahami negara yang melaksanakan diplomasi publik tersebut, sehingga diharapkan akan menguntungkan bagi kebijakan luar negeri negara pelaksana. Sebagai contoh adalah pendirian America House di Jerman pada tahun 1949, yang berguna sebagai pusat informasi mengenai Amerika Serikat (Tuch 2009). Pusat informasi ini dikonsep oleh pemerintah dan dieksekusi oleh pemerintah (Tuch 2009), sehingga relatif mudah untuk memastikan pencapaian kepentingan negara. Akan tetapi, diplomasi publik kemudian mengalami perluasan aktor dalam pelaksanaannya. Pada awal kelahirannya, diplomasi publik dilaksanakan oleh pemerintah sebagai inisiator, konseptor dan aplikator, sedangkan saat ini diplomasi publik dapat menjadi upaya yang dilaksanakan oleh pemerintah, pemerintah dan masyarakat negaranya 
atau murni masyarakat negara. Hal yang menarik adalah bahwa Korean wave lebih banyak dilaksanakan oleh aktor swasta , sehingga dengan mengandalkan aktor swasta sebagai pelaksana diplomasi publik, pertanyaan kemudian muncul terkait dapatkah diplomasi publik yang melibatkan aktor swasta ini mencapai kepentingan negara? Tulisan ini bertujuan untuk meneliti pencapaian kepentingan Korea Selatan melalui Korean wave. Untuk tujuan tersebut, penullis membagi tulisan ini menjadi tiga bagian yang dimulai dari penjabaran mengenai Diplomasi Publik secara konseptual, kepentingan yang ingin dicapai Korea Selatan melalui pelaksanaan diplomasi publik dan pencapaian diplomasi publik Korean wave di kota Padang.

\section{Konsep Diplomasi Publik}

Istilah Diplomasi Publik pertama kali diaplikasikan pada proses "international information and cultural relations" pada tahun 1965, yang dilaksanakan oleh Edmund Gullion, mantan diplomat Amerika Serikat yang kemudian menjadi dekan di Fletcher School of Diplomacy, Universitas Tufts yang berlokasi tidak jauh dari Boston (Cull 2009). Penggunaan istilah diplomasi publik kemudian berkembang dan negara-negara Eropa seperti Perancis, Italia, Jerman dan Inggris mulai mengikuti jejak Amerika Serikat dan melaksanakan diplomasi publik (Cull 2009).

Pada awal pelaksanaannya, diplomasi publik merupakan sebuah upaya yang dilaksanakan oleh pemerintah suatu negara untuk merangkul publik asing dengan harapan publik asing tersebut akan mendukung kebijakan luar negeri dari negara pelaksana diplomasi publik. Tuch (1990) mendefinisikan bahwa diplomasi publik merupakan sebuah proses komunikasi dengan publik asing dengan tujuan untuk memberikan pemahaman mengenai gagasan-gagasan dan cita-cita negara, institusiinstitusi dan budaya negara, termasuk tujuan nasional dan kebijakan negara saat itu. Tidak jauh berbeda, Nye (2008) berargumen bahwa diplomasi publik merupakan instrumen yang digunakan oleh pemerintah untuk memobilisasi sumber-sumber daya tarik yang dimilikinya untuk berkomunikasi dan menarik publik di luar negaranya. Serupa dengan definisi terdahulu, Rana (2011) memberikan definisi Diplomasi Publik sebagai aktivitas-aktivitas yang dilakukan oleh pemerintah dengan menggandeng agen-agen bukan negara untuk menjangkau publik dan aktor-aktor non-official di luar negeri untuk memberikan informasi, budaya, pendidikan dan citra negara.

Pelaksanaan diplomasi publik tradisional bersifat government driven, dimana pemerintah berperan besar dalam pelaksanaan diplomasi publik. Dari ketiga penjelasan ahli diatas, dapat disimpulkan bahwa diplomasi publik tradisional memiliki beberapa komponen pendukung yang diantaranya adalah: (1) pemerintah sebagai penyelenggara diplomasi publik; (2) publik asing yang merupakan sasaran pelaksanaan diplomasi; (3) informasi, budaya, pendidikan dan sumber-sumber atraksi negara sebagai media yang digunakan untuk melaksanakan diplomasi publik; dan (4) ketertarikan dan keberpihakan publik asing sebagai tujuan pelaksanaannya.

Definisi diplomasi publik ini kemudian meluas seiring dengan makin besarnya peran publikdalam pelaksanaannya, sehingga kemudian keluarlah terminologi "thenewpublic diplomacy". Pada pemahaman diplomasi publik yang baru, aktor yang melaksanakan diplomasi publik berkembang menjadi bukan hanya negara (pemerintah) tetapi dapat juga melibatkan masyarakat negara tersebut dan bahkan bisa jadi hanya masyarakat 
yang menginisiasi pelaksanaan diplomasi publik ini (private driven). Sejalan dengan penjabaran tersebut, Snow (2009) berargumen bahwa diplomasi publik merupakan sebuah aktivitas dimana pemerintah maupun individu dan kelompok mempengaruhi secara langsung ataupun tidak langsung terhadap sikap dan opini publik asing karena publik asing ini terkait langsung dengan kebijakan luar negeri nya. Sementara itu Cull (2009), menjelaskan bahwa perluasan aktor ini kemudian menghasilkan kebingungan tersendiri jika dikaitkan dengan pencapaian kepentingan negara, karena agak sulit untuk mengontrol aktor non-negara untuk dapat mencapai kepentingan yang telah ditargetkan oleh negara.

Diplomasi publik merupakan sebuah instrumen penting dalam menghasilkan soft power, yang merupakan power yang penting selain hard power. Nye (2009) berargumen bahwa soft power merupakan sebuah pendekatan yang lebih mengutamakan penggunaan daya tarik, daripada penggunaan kekerasan. Dengan menggunakan daya tarik ini diharapkan orang akan melakukan apa yang diinginkan dengan sukarela, tanpa merasa terpaksa. Ketika publik asing telah memiliki kerelaan dalam melaksanakan apapun yang diinginkan oleh negara pelaksana diplomasi publik, maka pada saat itulah soft power dihasilkan. Hal ini akan memudahkan negara dalam mencapai kepentingannya. Pada dasarnya, walaupun terjadi shifting dalam pemahaman terhadap diplomasi publik, akan tetapi secara umum kegiatan ini tetap ditujukan untuk mencapai kepentingan suatu negara. Dalam kaitannya dengan tulisan ini, Korean wave merupakan pelaksanaan diplomasi publik yang didominasi oleh aktor swasta yang memiliki kepentingan mereka sendiri, sehingga menarik untuk mengetahui pencapaian kepentingan negara melalui Korean wave.

\section{Korean wave sebagai Instrumen Diplomasi Publik}

Korean wave atau Hallyu dalam bahasa Korea merupakan fenomena meledaknya popularitas produk budaya populer negara ginseng ke luar negaranya. Istilah Korean wave pertama kali di populerkan oleh media Cina, sebagai respon dari booming nya beberapa produk budaya Korea Selatan di Cina pada tahun 1990-an (Jang dan Paik 2012). Pelaksanaan Korean wave menggunakan berbagai macam produk populer negara ginseng. Gunjoo Jang dan Won K. Paik (2012) mencatat berbagai produk budaya yang digunakan dalam Korean wave meliputi drama televisi, film, musik populer (K-Pop), dance (B-boys) dan untuk tingkat yang lebih rendah seperti video games, makanan, fashion, pariwisata dan bahasa.

Produk budaya yang beragam ini menciptakan fenomena kesuksesan di berbagai negara. Cheng (2008) berargumen bahwa "Hallyu consisted of an almost viral popularity of Korean popular culture throughout Asia. Korean pop music (K-pop) and Korean television dramas and movies dazzled audiences from Tokyo to Taipei, and quickly spread throughout Southeast Asia". Kesuksesan ini juga tercatat di negaranegara Timur Tengah, Afrika dan negara Asia lainnya (Cheng 2008). Kesuksesan produk budaya Korea dalam merambah pasar dunia disebabkan oleh beberapa aspek yang disenangi oleh masyarakat dunia seperti ; pemandangan yang indah, budaya yang menarik, pakaian dan model rambut yang kekinian, rasa nasionalisme yang tinggi dan lain-lain (Pare \& Min 2013). Selain itu, kesuksesan Korean wave juga tidak terlepas dari koordinasi yang solid dari berbagai aktor yang terlibat, karena industri Korean wave bukanlah industri yang "diurusi" oleh pemerintah. Hal ini dapat terlihat dari 
pernyataan Menteri Kebudayaan, Olahraga dan Turisme Kim Jongdeok yang dikutip oleh Shon (2016) :

We, the Korean government and the culture ministry, support the work they want to make, but we would not take any role or whatsoever as a decision maker or in getting involved in the actual working process at all. It's the working people, I mean, film makers or singers, who take the lead in actually promoting the Korean Wave outside South Korea

Terlihat bahwa beberapa aktor yang berontribusi terhadap kesuksesan Korean wave ini diantaranya adalah para pelaku industri perfilman, musik, makanan, fashion dan lain-lain, sementara keterlibatan pemerintah mencangkup pemberiaan dukungan terhadap industri ini.

Korean wave dinyatakan sebagai elemen diplomasi publik merujuk pada klaim pemerintah melalui website Kementerian Luar Negerinya. Pemerintah Korea Selatan berkomitmen untuk terus mendukung dan melestarikan setiap kegiatan yang menggunakan budaya populer ini. Penggunaan Korean wave sebagai instrumen diplomasi publik terlihat dari pernyataan dibawah ini :

Hallyu (the Korean wave) serves as an important element of Korea's public diplomacy. Thus, MOFA conducts statistical research on the current status of Hallyu in each country. Based on the results of such research, MOFA has provided support for Hallyu fan clubs' voluntary activities. With Hallyu as a medium, it has been seeking to promote communication among people with different cultural backgrounds (MoFA Republic of Korea).

Selanjutnya, keseriusan dalam mendukung pengembangan produk-produk Korean wave dapat dilihat dari berbagai kegiatan yang dilaksanakan oleh pemerintah. Hal ini terlihat jelas dari keterangan yang dilansir oleh kementerian luar negeri dalam buku putih diplomatik pada tahun 2016 lalu :

MOFA has contributed to the overseas advancement of hallyu cultural contents and to the continuous expansion of the Korean Wave through its network of Korean missions abroad. MOFA has hosted various events such as the K-Pop and K-Food World Festival, the Quiz on Korea and video contests while working in cooperation with broadcasters such as KBS, MBC and Arirang TV. In addition, it has conducted statistical research on the current status of hallyu in each region and has provided support for hallyu fan clubs' voluntary activities (MoFA Republic of Korea).

Pemerintah Korea Selatan menyadari sepenuhnya bahwa diplomasi publik merupakan instrumen yang esensial dalam mencapai kepentingan negaranya dan karenanya meningkatkan fokus dan kerja keras mereka dalam melaksanakan diplomasi publik. Website MOFA menjelaskan bahwa:

....the Ministry of Foreign Affairs (MOFA) has moved beyond the sphere of traditional government-oriented diplomacy by increasing its focus on public diplomacy, which includes reaching out to the foreign public through the arts, knowledge sharing, media, language, and aid. MOFA has worked hard to establish public diplomacy as the third pillar of its foreign policy along with political and economic affairs (MoFA Republic of Korea).

Untuk memperlihatkan keseriusan mereka dalam memanfaatkan penggunaan aset soft power mereka, pada diplomatic paper tahun 2016 bab 3, mereka menjelaskan 
bahwa Korea Selatan telah meningkatkan dana untuk pelaksanaan diplomasi publik ini.

Ketiga kutipan dari situs MoFA diatas telah memperlihatkan bahwa Korea Selatan memandang Korean wave sebagai instrumen yang penting dalam pelaksanaan diplomasi publik negara tersebut, sehingga pemerintah menaruh perhatian serius dalam pengembangan segala produk yang terdapat di dalamnya.

Sejalan dengan itu, Lee (2011) meyatakan bahwa Korea Selatan memandang bahwa menghasilkan soft power merupakan strategi yang penting bagi mereka, karena negara ini melihat bahwa pencapaian ekonomi dan militernya jauh lebih baik jika dibandingkan dengan pencapaian diplomasinya, sehingga penting bagi Korea Selatan untuk meningkatkan soft power nya. Salah satu instrumen yang digunakan untuk meningkatkan soft power adalah Korean wave, yang merupakan sebuah pelaksanaan diplomasi publik dengan melibatkan pemerintah dan masyarakat Korea. Masyarakat yang dimaksud disini bukanlah masyarakat umum, tetapi lebih kepada industriindustri kebudayaan yang ada di negara tersebut, seperti industri per-filman, industri musik, industri makanan dan industri-industri yang berkaitan dengan budaya lainnya.

\section{Kepentingan Yang Ingin Dicapai oleh Korea Selatan melalui Diplomasi Publik}

Pembicaraan mengenai diplomasi publik tidak dapat dilepaskan dari pembicaraan mengenai kepentingan negara yang salah satunya adalah pembentukan image (citra). Biasanya, diplomasi publik dilaksanakan untuk membentuk atau memperbaiki image yang telah ada sebelumnya, seperti yang coba dilakukan oleh Korea Selatan melalui pelaksanaan diplomasi publik. Pemerintah Korea Selatan terlihat memiliki perhatian yang sangat besar terhadap permasalahan image ini. Dalam diplomatic white paper 2016 dijelaskan bahwa : "MOFA...... tried to revise the distorted image of Korea described in foreign media or textbooks". Salah satu distorted image tersebut dijelaskan oleh Elfing-Hwang (2013); bahwa di dunia Barat, memori mengenai perang Korea sulit untuk dihapuskan, sementara itu perilaku Korea Utara yang kurang baik sering dikaitkan dengan Korea Selatan karena kebanyakan orang awam menganggap bahwa mereka merupakan satu negara Korea. Lebih lanjut lagi, hasil survei NBI tahun 2008 menunjukkan bahwa pemikiran mengenai serikat militan dan protes yang penuh kekerasan merupakan hal pertama yang muncul di pikiran audience pada saat mereka berpikir mengenai Korea (Cheng 2008).

Selain hal diatas, Se Jung Park dan Yon Soo Lim (2014) menambahkan bahwa citra Korea Selatan lebih tertinggal dari keadaan ekonomi dan pembangunan sosialnya. Korea Selatan memiliki prestasi yang sangat baik dalam pencapaian ekonominya, begitu juga dengan pencapaian militer. Citra negara yang buruk sepertinya ditakutkan akan mengganggu keberhasilan dari sektor-sektor lain. Hal ini sejalan dengan pernyataan presiden Lee Myung-bak pada tahun 2008 "if the nation wants to be labeled an advanced country, it will be necessary to significantly improve its image and reputation" (Cheng 2008). Terdapat dua hal yang dapat disimpulkan dari kutipankutipan diatas; pertama kepentingan Korea Selatan berkaitan dengan perbaikan image yang melekat pada mereka dan yang kedua, dapat diasumsikan bahwa Korea Selatan perlu memberikan pemahaman bahwa terdapat dua negara Korea berbeda yaitu Korea 


\section{Selatan dan Korea Utara.}

Image telah lama dianggap penting bagi sebuah negara. Negara-negara besar selalu berupaya untuk memperbaiki image nya dimata negara lain, karena image yang baik dianggap akan dapat memperlancar berbagai kepentingan mereka, baik itu kepentingan ekonomi dan kepentingan lainnya yang berkaitan dengan kebijakan negara mereka. Image buruk Korea Selatan ini cukup mengganggu bagi negara yang menginginkan citra baik dimata dunia, sehingga negara ini gencar dalam melaksanakan upaya perbaikan. Korea Selatan menginginkan pandangan positif dunia terhadap mereka, mereka ingin dikenal sebagai negara yang menarik. Dalam pidatonya pada tanggal 15 Agustus 2008, presiden Lee Myung-Bak menyatakan bahwa "Our traditional culture, when coupled together with our technological prowess, will no doubt transmit to the world an image of a more attractive Korea" (Cheng 2008). Keinginan untuk menciptakan image Korea Selatan yang attactive dengan memanfaatkan budaya dan teknologi kemudian diwujudkan dengan penciptaan tagline attractive Korea dengan harapan akan terbentuk sebuah citra pada masyarakat asing bahwa negara gingseng ini merupakan negara yang menarik dalam segala hal.

Selain permasalahan image dan pembedaan negara, terdapat permasalahan keamanan di Semenanjung Korea yang menjadi concern besar pemerintah Korea Selatan. Telah menjadi pengetahuan umum bahwa keamanan di Semenanjung Korea tidaklah stabil. Tindakan uji coba nuklir yang dilakukan oleh Korea Utara sebanyak dua kali pada tahun 2006 dan tahun 2009 lalu, memberikan perasaan tidak aman bagi Korea Selatan. Perasaan tidak aman tersebut tergambar jelas dengan menyinggung permasalahan keamanan semenanjung Korea di awal sambutan menteri luar negeri Yun Byung-se pada bulan Desember 2016 pada Diplomatic White Paper nya. Selain itu, perasaan tidak aman tersebut ditindaklanjuti dengan secara aktif mendorong terciptanya mekanisme multilateral untuk menghentikan upaya pengembangan nuklir Korea Utara. Pernyataan tegas di situs kementerian luar negeri negara ini memperkuat argumen diatas :"... while responding to North Korea's provocations in a stern manner by continuing to implement strong sanctions and apply pressure on North Korea in coordination with the international community (MoFA Republic of Korea). Selanjutnya, menteri luar negeri Yun Byung-se juga mencari dukungan dari negaranegara dunia untuk menjatuhkan sanksi kepada Korea Utara pada sidang Umum PBB pada tanggal 17 September 2016 (Yonhap News Agency).

Uraian diatas memperlihatkan bahwa Korea Selatan mencoba untuk menggugah masyarakat internasional bahwa masyarakat internasional perlu untuk memberikan tekanan terhadap Korea Utara terkait sikap negara ini dalam mengembangkan nuklir. Lebih lanjut, Korea Selatan seperti memberikan giringan bahwa sikap Korea Utara ini membahayakan untuk masyarakat internasional,sehingga dibutuhkan bantuan dari masyarakat internasional untuk turut memberikan tekanan agar Korea Utara mengubah sikapnya.

Terdapat beberapa kesimpulan mengenai kepentingan yang ingin dicapai oleh Korea Selatan; pertama, Korea Selatan ingin menghapuskan memori lama terkait perang Korea yang membuat mereka dikenal sebagai negara yang penuh kekerasan. Kedua, Korea Selatan ingin memperlihatkan bahwa Korea Selatan dan Korea Utara bukanlah satu negara yang sama. Ketiga, Korea Selatan ingin dilihat sebagai negara yang attractive ,image yang berguna untuk menopang kemajuan ekonomi dan militer mereka selama ini. Keempat, terlihat indikasi bahwa pemerintah Korea Selatan ingin 
masyarakat internasional memberikan tekanan terhadap pengembangan nuklir yang dilakukan oleh Korea Utara. Korean wave dikatakan sebagai elemen penting dalam diplomasi publiknya oleh pemerintah Korea Selatan, sehingga selayaknyalah Korean wave menjadi salah satu "senjata" dalam mencapai kepentingan diatas.

\section{Diplomasi Publik Korean Wave di kota Padang}

Seperti halnya negara-negara Asia Timur, negara-negara Asia Tenggara juga dilanda demam Korean wave. Diantara negara Asia Tenggara tersebut adalah Indonesia, negara yang secara spesifik tidak disebutkan oleh Korea Selatan sebagai negara target diplomasi publiknya. Penulis mencoba untuk mengerucutkan riset ini pada mahasiswa dikota Padang, Sumatera Barat dimana demam Korean wave terlihat jelas dari kegandrungan mahasiswa untuk menonton drama Korea, berandan ala Korea, berpakaian ala Korea dan mempraktekkan bahasa Korea dalam percakapan seharihari. Hasil preliminary survei yang penulis lakukan memperlihatkan bahwa jumlah mahasiswa yang menggemari produk Korean wave sangatlah banyak, yang mencapai $64 \%$ dari jumlah mahasiswa yang disurvei. Angka ini jauh meninggalkan budaya populer lainnya yakni Japanese wave yang hanya 34\%. Untuk drama Korea, penulis menemukan bahwa rata-rata penggemar Korean wave ini menghabiskan waktu 1-6 jam sehari untuk menonton drama Korea melalui berbagai media, seperti media internet dan televisi. Sebagai dampak lanjut dari kegemaran mereka mengkonsumsi budaya populer Korea ini, mereka menjadi memiliki keinginan yang sangat besar untuk mengunjungi Korea Selatan. Ini terlihat jelas dari hasil survei bahwa sebanyak 79\% audience menyatakan keinginan untuk mengunjungi Korea Selatan, termasuk keinginan untuk mengikuti pertukaran pelajar atau bahkan melanjutkan studinya di disana.

Tertarik dengan hasil temuan tersebut, penulis mencoba untuk memperluas wilayah survei dan memperbanyak jumlah responden, untuk mendapatkan sebuah hasil yang valid mengenai keberhasilan Korean wave dalam mencapai kepentingan Korea Selatan. Untuk mencapai tujuan tersebut, penulis melakukan survei ke 10 universitas besar di Padang, dengan responden survei diambil secara purposive. Penulis kemudian melakukan penyebaran kuesioner kepada responden tersebut dan mengolah data untuk dapat menjawab pertanyaan penelitian ini.

Korean wave berhasil mencapai popularitas di kota Padang. Kawula muda di kota ini aktif dalam mengkonsumsi produk drama, K-Pop dan produk-produk lainnya. Hasil survei awal penulis menunjukkan tingkat intensifitas konsumsi yang tinggi dari kawula muda kota Padang terhadap produk budaya Korea Selatan ini. Bagian ini mencoba melihat apakah kepentingan yang ingin dicapai oleh pemerintah Korea Selatan telah tercapai seiring dengan boomingnya Korean wave. Telah dijelaskan sebelumnya bahwa yang ingin dicapai oleh Korea Selatan melalui pelaksanaan diplomasi publik adalah menghapus image buruk mengenai perang Korea dulu dan menggantinya dengan image Korea Selatan yang attractive, ingin membentuk pembedaan secara jelas antara Korea Utara dan Korea Selatan dan secara implisit negara ini juga mengharapkan keberpihakan lingkungan internasional terhadap negara mereka terkait konflik di semenanjung Korea.

Penulis menemukan beberapa hal melalui survei yang kami lakukan kepada 
mahasiswa di 10 universitas di kota Padang. Pertama, kesukaan pemuda-pemudi ini terhadap Korean wave ternyata tidak diikuti oleh terbangunnya rasa penasaran mereka terhadap pemerintahan negara Korea Selatan. Terbukti lebih dari 3/4 (78\%) responden menyatakan bahwa mereka tidak pernah membaca kebijakan negara Korea Selatan dan sama sekali buta terhadap kebijakan tersebut. Para mahasiswa ini tidak pernah mengakses website-website pemerintah yang merupakan tempat dimana pemerintah menyebarluaskan kebijakan-kebijakan mereka. Kenyataan ini sebenarnya cukup memprihatinkan, mengingat pelaksanaan diplomasi publik biasanya dikaitkan dengan upaya negara untuk mensosialisasikan kebijakan negaranya kepada negara lain. Dengan tersosialisasinya kebijakan negaranya, negara berharap dapat mengurangi kesalahpahaman mengenai tujuan mereka yang sesungguhnya, sehingga pelaksanan kebijakan dapat berjalan lebih lancar. Telah dijelaskan sebelumnya bahwa Korea Selatan terganggu dengan perilaku Korea Utara yang mengembangkan nuklir dan mengadakan beberapa kali percobaan nuklir. Korea Selatan menginginkan adanya sebuah mekanisme internasional untuk menyelesaikan permasalahan ini. Keinginan ini dipublikasikannya di diplomatic white paper tahun 2016 dan website kementerian luar negerinya. Idealnya, jika diplomasi publik ini berhasil, masyarakat asing akan tertarik untuk mempelajari kebijakan ini dan kemudian bisa terpengaruh akan keinginan Korea Selatan dan kemudian bersepakat dengan Korea Selatan. Fakta bahwa mayoritas responden tidak pernah membaca kebijakan negara Korea Selatan merupakan sebuah indikasi tidak berhasilnya tujuan diplomasi publik untuk pencapaian kepentingan negara.

Kedua, pemerintah ingin menciptakan image yang positif dengan mengeluarkan tag line "Attractive Korea", yang melaluinya pemerintah berharap negara mereka akan dianggap sebagai negara yang menarik untuk dikunjungi dan lebih lanjut diajak untuk bekerjasama. Sayangnya, sekitar $72 \%$ dari responden mahasiswa tidak mengetahui tag line tersebut dan lebih lanjut tidak memahami tujuan dari penciptaan semboyan tersebut. Terdapat dua asumsi disini; asumsi pertama adalah bahwa produk budaya populer ini tidak berhasil dalam memberikan pemahaman mengenai tag line tersebut atau hal kedua, bisa jadi tidak terdapat konten yang memberikan pemahaman tersebut kepada para responden sehingga bukanlah fenomena yang mengejutkan ketika pesan tersebut tidak sampai. Asumsi kedua ini memerlukan penelitian yang lebih dalam lagi sebelum memutuskannya menjadi sebuah fakta.

Walaupun terbilang gagal dalam memberikan pemahaman mengenai attractive Korea, dari segi promosi pariwisata, drama-drama Korea telah berhasil memberikan kesan akan indahnya pemandangan alam Korea, menariknya kuliner mereka, indahnya kebudayaan mereka dan menariknya penduduk Korea Selatan ini. Hal ini kemudian membuat responden ingin berkunjung ke Korea Selatan suatu hari nanti. Disini penulis melihat bahwa terdapat sebuah missing the real message, bahwa mahasiswa tidak benar-benar memahami pesan yang ingin disampaikan oleh pemerintah Korea Selatan melalui tag line tersebut; yang sebenarnya juga ingin menciptakan kesan Korea Selatan sebagai negara yang cinta damai. Hal ini mungkin saja terjadi karena rendahnya minat mereka dalam membaca berita-berita dari Pemerintah Korea Selatan.

Selanjutnya merujuk pada keinginan Korea Selatan agar masyarakat internasional dapat memberikan tekanan kepada Korea Utara melalui pembuatan mekanisme penghentian pengembangan nuklir yang dibuat oleh negara ini, maka dapat diasumsikan bahwa membentuk image sebagai negara yang cinta damai sangatlah penting, karena dengan alasan menciptakan perdamaian di Korea peninsula dan wilayah sekitarnya merupakan 
alasan yang selalu diusung oleh Korea Selatan. Langkah selanjutnya yang ingin dipastikan oleh Korea Selatan adalah agar masyarakat internasional mendapatkan image bahwa negara ini adalah negara yang cinta damai. Penulis menemukan bahwa para mahasiswa penggemar budaya populer Korea ini memang merasa bahwa Korea Selatan adalah negara yang cinta damai.

Dari uraian diatas, terlihat bahwa pelaksanaan diplomasi publik yang melibatkan banyak aktor privat sulit untuk mencapai kepentingan negara. Seperti halnya diplomasi publik Korean wave yang melibatkan aktor-aktor privat dari dunia entertainment, yang berhasil menarik banyak penonton, meningkatkan animo masyarakat untuk tetap mengkonsumsi produk budaya, meningkatkan keinginan untuk berkunjung ke Korea, akan tetapi sayangnya pesan yang ingin disampaikan oleh pemerintah kurang tercapai. Seperti misalnya kalangan umum terbius oleh gangnam style yang dipopulerkan oleh Psy, menirukan gerakannya, tetapi tanpa pesan yang terkait dengan negara Korea. Mungkin gerakan-gerakan yang dibuat artis ini memberikan kesan akan Korea Selatan yang atraktif, tetapi sayangnya ketika masyarakat tidak terangsang untuk membaca lebih lanjut mengenai tagline attractive Korea dari situs-situs resmi pemerintah, sulit untuk mempengaruhi masyarakat umum untuk berpikir seperti yang diinginkan oleh pemerintah.

Produk budaya populer ini dapat berkonstribusi terhadap pendapatan negara Korea Selatan dan meningkatkan perasaan dekat dan familiar dengan Korea Selatan pada masyarakat pengkonsumsi produk ini, akan tetapi hal ini tidak dapat sepenuhnya berkontribusi terhadap pencapaian kepentingan pemerintah termasuk pembentukan image yang diinginkan.

\section{Simpulan}

Korea Selatan melaksanakan diplomasi publik untuk mencapai beberapa kepentingan seperti; menghapuskan image sebagai negara yang penuh kekerasan, memberikan pengetahuan bahwa terdapat dua negara yang berbeda di semenanjung Korea dan menciptakan image mengenai Korea Selatan yang attractive dan keinginan untuk menyatukan pendapat masyarakat dunia terkait permasalahan nuklir Korea Utara. Korean wave dikatakan oleh pemerintah Korea Selatan sebagai salah satu instrumen yang dalam pelaksanaan diplomasi publiknya yang bisa jadi dikarenakan kesuksesan Korean wave yang luar biasa diberbagai dunia. Tulisan ini menemukan bahwa kepopuleran dan kesuksesan pelaksanaan diplomasi publik melalui penggunaan budaya populer yang dilaksanakan oleh aktor private belum sepenuhnya dapat diartikan sebagai kesuksesan yang diinginkan oleh pemerintah. Budaya populer Korea Selatan sangat terkenal dikalangan kawula muda di kota Padang, tetapi ternyata sukses dan booming nya budaya populer ini tidak dapat mencapai kepentingan negara yang telah diuraikan diatas.

Secara umum, Korean wave berhasil mencapai tujuan untuk memperkenalkan Korea ke masyarakat asing. Akan tetapi jika ditinjau lebih dalam lagi, Korean wave belum berhasil dalam mencapai kepentingan yang diinginkan oleh pemerintah. Pelaksanaan diplomasi publik yang ditujukan untuk pencapaian kepentingan negara haruslah mendapatkan koordinasi yang intens dari pemerintah, sehingga pemerintah dapat ikut campur dalam menyertakan konten yang mendukung kepentingan negara pada 
produk budaya yang dihasilkan oleh aktor swasta tersebut. Dengan demikian, program pemerintah dapat ikut tersosialisasikan dalam setiap produk yang dikonsumsi oleh masyarakat internasional, sehingga produk budaya seperti Korean wave tidak hanya menjadi penghasil ekonomi yang besar, tetapi juga membantu mencapai kepentingan pemerintah terkait hal-hal yang telah disebutkan diatas.

\section{Referensi}

\section{Buku dan Bab dalam Buku}

Cheng, Li-Chih, 2008. "The Korea Brand : The Cultural Dimension of South Korea's Branding Project in 2008", The SAIS-U.S-Korea Yearbook 2008, Jhons Hopkins University Press.

Lee, S.J., 2011. "South Korean soft power and how South Korea views the soft power of others". In Public Diplomacy and Soft Power in East Asia. Palgrave Macmillan: New York.

Rana, Kishan S, 2011. 21st Century Diplomacy: A Practicioner's Guide, New York: Bloomsbury Publishing USA

Snow, Nancy, "Rethinking Public Diplomacy" in Routledge Handbook of Public Diplomacy (ed), New York: Routledge.

Tuch, Hans, 1990. Communicating with the World. US Public Diplomacy Overseas, New York: Macmillan.

\section{Jurnal dan Jurnal Daring}

Cull, N.J., 2009. "Public diplomacy: Lessons from the past". CPD Perspectives on Public diplomacy, 2 (19).

Gunjoo, Jang \& Won K. Paik, 2012. "Korean Wave as Tool for Korea’s New Cultural Diplomacy", Advances in Applied Sociology. 2 (3).

Jeong, Jae-seon, Lee, Seul-hi dan Lee, Sang-gil, 2017. "When Indonesian Routinely Consume Korea Pop Culture: Revisiting Jakartan Fans of the Korean Drama Dae Jang Geum”, International Journal of Communication 11.

Nye Jr, J.S., 2008. "Public diplomacy and soft power". The annals of the American academy of political and social science, 616 (1).

Parc, J. and Hwy-Chang, M., 2013. "Korean dramas and films: Key factors for their international competitiveness". Asian Journal of Social Science, 41 (2).

Park, Se Jung dan Lim, Yon Soo, 2014. "Information networks and social media use in public diplomacy: a comparative analysis of South Korea and Japan", Asian Journal of Communication, 24 (1).

\section{Artikel Daring}


Sohn, Jiae, "Content producers lead Korean Wave", Korea.net [daring] http://www. korea.net/NewsFocus/Culture/view?articleId=134924 [diakses pada 1 Juni 2018]

Tuch, Hans N, "How Public Diplomacy Worked in Practice", [daring] http://www.unc. edu/depts/diplomat/item/2009/1012/fsl/fsl tuch.html [diakses pada 15 Januari 2015]

Yonhap News Agency, "S. Korea to go all out to earn support for stronger U.N.-led sanctions against N. Korea" [daring] http://english.yonhapnews.co.kr/news/2016/o9 /10/0200000000AEN20160910001751315.html?m [diakses pada 14 November 2018]

\section{Lain-Lain}

Diplomatic White Paper 2016, Republic of Korea http://www.mofa.go.kr/eng/ brd/m 5684/list.do

MOFA Republicof Korea http://www.mofa.go.kr/eng/wpge/m 5474/contents.do

Tuk, William, The Korean Wave : Who are behind the success of Korean poplar culture?, Tesis Magister di Leiden University 